\title{
1 Impact of location of isolation valves on resilience of water distribution
}

systems

3 Mansoureh Atashi ${ }^{\mathrm{a} 1}$, Ali N. Ziaei ${ }^{\mathrm{a} 2 *}$, Saeed Reza Khodashenas ${ }^{\mathrm{a} 3}$ and Raziyeh 4 Farmani $^{\text {b }}$

$5 \quad{ }^{a}$ Department of Water Science and Engineering, Ferdowsi University of Mashhad, Mashhad,

6 Iran; ${ }^{b}$ Department of Engineering, University of Exeter, Exeter, UK

71 PhD student in Hydraulic structures, Department of Water Science and Engineering, Ferdowsi University of

8 Mashhad, Mashhad, Iran, e-mail: at.mansoureh@gmail.com

92 Associate Professor, Department of Water Science and Engineering, Ferdowsi University of Mashhad, Mashhad,

10 Iran, Corresponding Author, an-ziaei@um.ac.ir

113 Professor, Department of Water Science and Engineering, Ferdowsi University of Mashhad, Mashhad, Iran e-mail: 12 saeedkhodashenas@yahoo.fr

13 b Associate Professor, Department of Engineering, University of Exeter, Exeter, UK, e-mail: r.farmani@exeter.ac.uk 14 


\title{
1 Impact of isolation valves location on resilience of water distribution systems
}

3

4

\begin{abstract}
The isolation valves are crucial components of water distribution systems (WDS) that are used to shut down a segment of the network to repair or replace failed pipes. In this paper an algorithm to find adjacent valves to isolate a failed pipe was proposed and the global resilience analysis method was implemented to find out the critical segments based on the isolation valves. The method was applied to Net3 network with three different isolation valve configurations.

The location of isolation valves changed the resilience of the WDS considerably. The critical pipes and segments were also varied with different valve configuration. More than $60 \%$ of the most critical pipes are different between $\mathrm{N}$ valves and $\mathrm{N}-1$ valves configurations. The resilience of Limited valves configuration (with 52 valves) was $22 \%$ and $15 \%$ less than the resilience of $\mathrm{N}$ valves and $\mathrm{N}-1$ valves configurations with 228 and 105 valves respectively. Furthermore, with adding valves to the critical segments, the resilience can be enhanced noticeably.
\end{abstract}

Keywords: GRA; critical segments, supply shortage, reliability

Subject classification codes: include these here if the journal requires them

\section{1-Introduction}

Water distribution systems (WDS) are the crucial component of urban infrastructure that play a critical role in delivering sufficient water to users with acceptable pressure, volume and quality. Occurrence of a pipe failure may interrupt service, undermine system performance 
1 and ultimately lead to consumer dissatisfaction (Tabesh et al. 2009). More serious condition

2 occurs when several pipes in the system fail simultaneously (Gheisi and Naser 2014).

Nowadays, the threat of accidental or man-made disruptions motivates water utilities to plan risk mitigation works and to improve the preparedness for extreme events (Berardi et al. 2014). Pipe breaks increase with aging infrastructure, natural disasters such as earthquakes and man-made disruptions (Klise, Murray, and Haxton 2018). Three criteria; reliability, resiliency and vulnerability have been used to assess the performance of the water distribution system (Hashimoto, Stedinger, and Loucks 1982). The resilience capacities are absorptive, adaptive and restorative that a system needs to be able to respond to perceived or real shocks (Francis and Bekera 2014). Butler et al. (2017) defined the resilience in WDSs as "the degree to which the system minimizes level of service failure magnitude over its design life when subject to exceptional conditions". Failure modes in WDSs can be broadly categorized into structural failure and functional failure (Mugume et al. 2015). Response to pipe failure can indicate system resilience to loss of structural connectivity (Butler et al. 2014).

Todini (2000) proposed a technique based upon the definition of resilience index that emulate both reducing the cost and preserving a capability of the system to overcome failures while still satisfying demand and pressure at each node. Baños et al. (2011) analyzed the quality of several resilience indices, i.e., resilience index, RI (Todini, 2000), network resilience index, NRI (Prasad and Park (2004), modified resilience index, MRI (Jayaram and Srinivasan (2008) for WDSs. They showed that these resilience indices did not consider the location of over-demand occurrence. Monsef et al. (2019) evaluated six well-known reliability assessment indicators (RI, NRI, MRI, minimum surplus head (MSH), total surplus head (TSH), entropy reliability indicator (ERI)) in five WDSs under a large number of 
1 abnormal operating conditions. They showed that some WDS structures, in spite of having

2 higher reliability indicator values, are unable to adequately tolerate abnormal conditions.

Berardi et al. (2014) proposed an evolutionary strategy to assess WDS vulnerability with scenarios that a minimum fraction of failed pipes caused maximum shortage of water supply. For evaluating resilience, it is important to include high-stress scenarios that happen occasionally with low probability (Johansson et al., 2013). Identification of performance strains resulting from any stress magnitude requires no knowledge of the causal threats. This approach has been adopted in global vulnerability analysis (GVA) of power grids and for global resilience analysis of water distribution systems (Johansson, 2007; Hokstad et al., 2012; Johansson et al., 2013; Mugume et al. 2015; Diao et al., 2016). Diao et al. (2016) proposed the Global Resilience Analysis (GRA) as a methodology that focusses on the response to system failure modes. GRA provides an overview of a water system's resilience to various failure modes. For each failure mode, it identifies the range of corresponding failure impacts and reveals extreme scenarios. In most reliability researches, pipe breaks were modeled by removing individual pipes from a network model without considering the location of isolation valves (Fujiwara and Li 1998; Dandy and Engelhardt 2001). In the pipe failure mode of GRA, the stress is also modeled by isolating pipes shortly after breakage so that the 'failed pipes' have been modeled by changing the status of them to completely closed for a duration of 3 hours in peak demand period (Diao et al. 2016). This requires existence of two valves on both ends of each pipe so that each pipe can be repaired or replaced individually. In practice, a subsystem isolation is required to repair or to rehabilitate a failed pipe and usually done by closing the adjacent valves. In the other words, depending to availability of isolation valves more than one pipe may need to be closed to repair or replace a failed pipe. Isolation valves play a key role in management of WDSs for isolation of subsystems and flow or pressure control (Jun 2005; 
1 Walski, Weiler, and Culver 2008). Therefore, to isolate a portion of a network, isolation

2 valves must be considered in the network (Walski 1987; Jose and Sumam 2016; Walski $32002)$.

Walski (1993) showed the importance of adequate valving to enhance the reliability of WDSs. Walski (2002) proposed a method for fire flow simulation by closing individual 6 pipes versus segments. The results showed that the valves should be considered in connections to main pipes so that during a failure at a smaller line, the main pipes not to be part of a segment. Many studies have focused on identification of network segments and unintended isolation of the network by valve closure (Blokker et al. 2011; Giustolisi, Kapelan, and Savic 2008; Jun and Loganathan 2007). Kao and Li (2007) proposed a segmentbased model for pipeline replacement to improve water supply reliability. Several researchers including Giustolisi and Savic (2010), Creaco et al. (2010) and Pecci et.al.(2017) presented a method for optimal placement of valves in WDSs to increase network reliability.

The design guideline proposed by Mays (2000) suggested placing valves at both ends of each pipe. Ysusi (1999) also recommended the valves to be placed on each pipe at every junction to maximize the network performance. However, the number of valves in real networks is always less than this guideline due to budget constraints. There are also other general guidelines for valve placement in a WDSs (Lakes and Board 1992; Rosenthal, Mesman, and De Koning 2002). Based on these guidelines, the spacing between two valves should be less than $500 \mathrm{ft}$ in business area, and less than $800 \mathrm{ft}$ otherwise. At least two valves at a T-junction and three at a cross-section have been recommended. rule for modeling the impacts of isolation valves failure. The "N Valves" configuration is a valve layout where the number of valves is equal to the linked pipes at a junction, and "N-1 Valves" is a style of valving one less than the linked pipes (Jun and Loganathan 2007; Alvisi, 
1 Creaco, and Franchini 2011; Giustolisi and Savic 2010; Giustolisi, Berardi, and Laucelli

2 2014; Jose and Sumam 2016; Liu et al. 2017; Walski, Weiler, and Culver 2008). Giustolisi

3 (2018) developed a WDS reliability assessment indicator based on the supplied demand and a

4 modularity index for the isolation valve system (IVS) performance assessment. The network

5 performance was evaluated by risk of disconnection, i.e. the probability of segment failure

6 per the required customer demand over time.

Meng et al. (2018) proposed a framework based on graph theory for the optimized

8 placement of new valves based on resilience assessment. Resilience was measured by failure

9 severity in a segment (measured in L) as the production of the longest replacement time

10 (hours) of pipes in a segment and the unsatisfied water demand (L/h) due to valve closures

11 for repair. Unsatisfied water demand was assessed and the reduction in water delivery due to

12 low pressure was not considered. They studied single valve addition and the location of the

13 added valve was optimized.

14 In this paper, the global resilience is assessed by considering different valve 15 configurations including "N Valves", "N-1Valves" and "Limited Valves" in Net3 network 16 and the results are compared. An efficient algorithm to identify the isolation segment based 17 on adjacent valves to each pipe is also proposed. The critical pipes and segments in each valve configuration are specified based on GRA method.

\section{2- Method and material}

20 After pipe breaks, some damages are minor and therefore can be repaired, while other 21 damages are more serious and require a replacement of pipe sections. During reparation, 22 there may be no need to isolate the pipe, although the pipe will continue leaking until the 23 repair is finished, However, during a replacement, the isolation is necessary and fixing the broken pipe will not start until it is isolated using the necessary valves (Paez, Fillion, and 
1 Hulley 2018). In $\mathrm{N}$ valves configuration, each pipe can be isolated individually. While in the

2 other valve configurations, a method is required to find the adjacent isolation valves to isolate

3 a segment of the network to replace the failed pipe.

4

5 To model a pipe failure, it is required to close the corresponding isolation valves that separate

6 the segment including that pipe. Adding an isolation valve on each pipe in EPANET2, the

7 pipe is divided into three sections. Hence, an isolation valve acts as a short connector. To find

8 the isolation valves of each pipe, based on the start and end nodes of pipes and valves, all

9 nodes are searched.

The procedure to identify the adjacent isolation valves of each pipe after loading the network hydraulic model with existing valves is as follows (Figure ):

Step 1. Load basic WDS information.

Step 2. Separate pipe list and valve list with start and end nodes.

Step 3. Consider a pipe, the start and end nodes of that pipe are compared with all valves start and end nodes. Then three different situations may happen:

a- The start and end nodes of a pipe are the same as the start or end nodes of two different valves, which means that there exist two valves at both ends of that pipe.

b- One of the pipe start or end nodes is the same as a valve start or end nodes which means that there is a valve on one end of the pipe.

c- None of the pipe ends are the same as valves ends, which shows no valve in this pipe.

Step 4. In case (a) there are two valves at ends of the pipe, thus the pipe failures is modelled with simply closing the identified valves. In cases $b$ and $c$, one or two pipe 
ends are connected to adjacent pipes. For the connected pipes step 3 is repeated up to reaching an existing valve. Then the pipe and valve lists are updated for that segment. Step 5. Repeat the process to find all isolation segments.

As an example when pipe 2 (P2 in Figure ) is failed, three isolation valves should be closed (valves 1-3) to isolate this pipe. Therefore, four other pipes are also shut off (i.e., e1, e2, e3 and P3). When there are valves at both ends of each pipe (such as P4 in Fig. 2), the status of P4 simply changes to "closed" form in EPANET to model the pipe failure.

\section{2-2-Resilience analysis}

In this paper, the GRA approach is adopted to evaluate the system resilience under different pipe failure modes (Diao et al. 2016). The possible failure modes were modelled with increasing the stress magnitude and estimating the corresponding strains (Johansson 2007). Different combinations of pipe failure are considered as stress magnitude and ratio of unsupplied demand to total demand is defined as strain magnitude.

Due to huge number of possible combinations (a system with $\mathrm{N}$ component and $\mathrm{m}$ simultaneous failures has $\quad \sum \frac{n !}{m !(n-m) !}$ potential failure scenarios), it is not possible to model every conceivable scenario for each system failure magnitude (Sweetapple et al. 2018). For any given stress magnitude, an appropriate affordable number of failure scenarios must be determined. Where the total number of scenarios (TNS) is determined as follows (Diao et al. 2016): 


$$
T N S=\left\{\begin{array}{l}
1, \text { if } c=c_{f} \\
c, \text { if } c_{f}=1 \\
\frac{N \times P \times(1-P)}{\left(\frac{C I}{Z_{\alpha}}\right)^{2} \times(N-1)+P \times(1-P)}+2\left[c-\left(c_{f}-1\right)\right], \text { if } 1<c_{f}<c,
\end{array}\right.
$$
Marks 1988).

$$
q_{i}(t)=\left\{\begin{array}{l}
0, \text { if } \quad P_{i}(t) \leq 0 \\
Q_{i}(t) \sqrt{\frac{P_{i}(t)}{P_{\min }}}, \text { if } \quad 0<P_{i}(t)<P_{\min } \\
Q_{i}(t), \text { if } \quad P_{i}(t) \geq P_{\min }
\end{array}\right.
$$
where $Q_{i}(t)$ is the nodal demand expected to be supplied at junction i at time t; $P_{i}(t)$ is 
1 (in this paper it is considered as $20 \mathrm{~m}$ for nodes with specified demand, and $0 \mathrm{~m}$ for nodes

2 without); $q_{i}(t)$ is the estimated actual supplied nodal demand at junction $i$ at time $t$. demand to the total demand during strain duration (Eq. 3). The strain duration is the time between the first occurrence of supply failure and the final return to a non-failure mode (Diao 6 et al. 2016).

$$
d D_{f}=\frac{\sum_{T_{s s}}^{T_{S E}} \sum_{i}^{N}\left(q_{i}(t)-q_{i f}(t)\right)}{\sum_{T_{s s}}^{T_{S E}} \sum_{i}^{N} q_{i}(t)}
$$
where $q i(t)$ is the estimated actual supplied nodal demand at junction $i$ at time $t$ when there is no pipe failure; $q_{i f}(t)$ is the estimated actual nodal demand at junction $i$ at time $t$ in

9 failure scenario $f ; T_{S S}$ : start time of the strain (unsupplied demand); $T_{S E}$ : end time of the 10 strain; $N$ : the total number of junctions.

\section{2-3- Implementation algorithm}

12 A computer code was developed based on Eqs. 1-3, to implement the global resilience analysis method for pipe failure. The code calls the EPANET2 engine for hydraulic simulation (demand-driven) of the failure scenarios (Rossman 2000). The code estimates the demands at each node in the next step (by Eq 2). This process continues until there is no significant change in the node pressure (Pathirana 2010). To determine the impact of valves density on resilience of system to pipe failure, a WDS with three different isolation valve configuration (i.e., $\mathrm{N}$ Valves, $\mathrm{N}-1$ Valves and limited valves is considered. The isolation segments are identified based on the algorithm presented in previous section. The resilience analysis of the network is evaluated based on an algorithm presented in Figure 3. 
1 The Net3 network was considered to evaluate the effect of isolation valves on resilience

2 analysis. This case study was used as a benchmark network in global resilience analysis by

3 Diao et al. (2016). Based on suggested guidelines for valve placement, the spacing between

4 two valves should be less than $500 \mathrm{ft}$ in business area, less than $800 \mathrm{ft}$ in other areas (Lakes

5 and Board 1992; Mays 2000; Rosenthal et al., 2002). At least two valves at a T-junction and

6 three at cross sections and no more than four valves for segment isolation should be

7 implemented. Therefore, three different valve configurations are considered for Net3. The

8 valves location in the Limited valve configuration was selected based on suggested guidelines

9 and engineering judgment. The properties and configurations are summarized in Figure 4 and

10 Table 1.

13 4-Results and discussion

14 In this section, to show the effect of connecting reservoir pipes (CRPs) to the distribution 15 network on network resilience, these pipes were analysed first. Then the system resilience 16 with three different valve configurations are discussed.

\section{4-1- Resilience of CRPs}

18 In Figure 5 the resilience of Net3 for two approaches (i.e., whole network (WN), and network

19 without CRP (NWCRP)) are compared. The GRA showed that Net3 encountered complete

20 failure due to simultaneous failure of the four main CRPs. Whereas excluding these pipes

21 from the resilience analysis showed that the failure of 12 pipes lead to the complete supply

22 failure.The maximum and average network supply shortage were $36 \%$ and $12 \%$ higher than

23 the whole network model. The supply shortage for all combinations of CRP failures in the

24 peak demand period $(18-20 \mathrm{pm})$ is presented in Figure 6. Based on this analysis, the most 
1 critical pipes are $1,4,2,3,5$ (pipes connected to tank 3 , the river, tank 1 , tank 2 and the lake,

2 respectively). Since the pumping from the lake did not occur during this period, pipe 5

3 acquired the least priority. The supply shortage for different combinations of CRP failures is

4 illustrated in Figure 7. Duplication of these four main pipes, can enhance the network 5 resilience up to $36 \%$.

\section{4-2- Valve configuration effects}

7

8

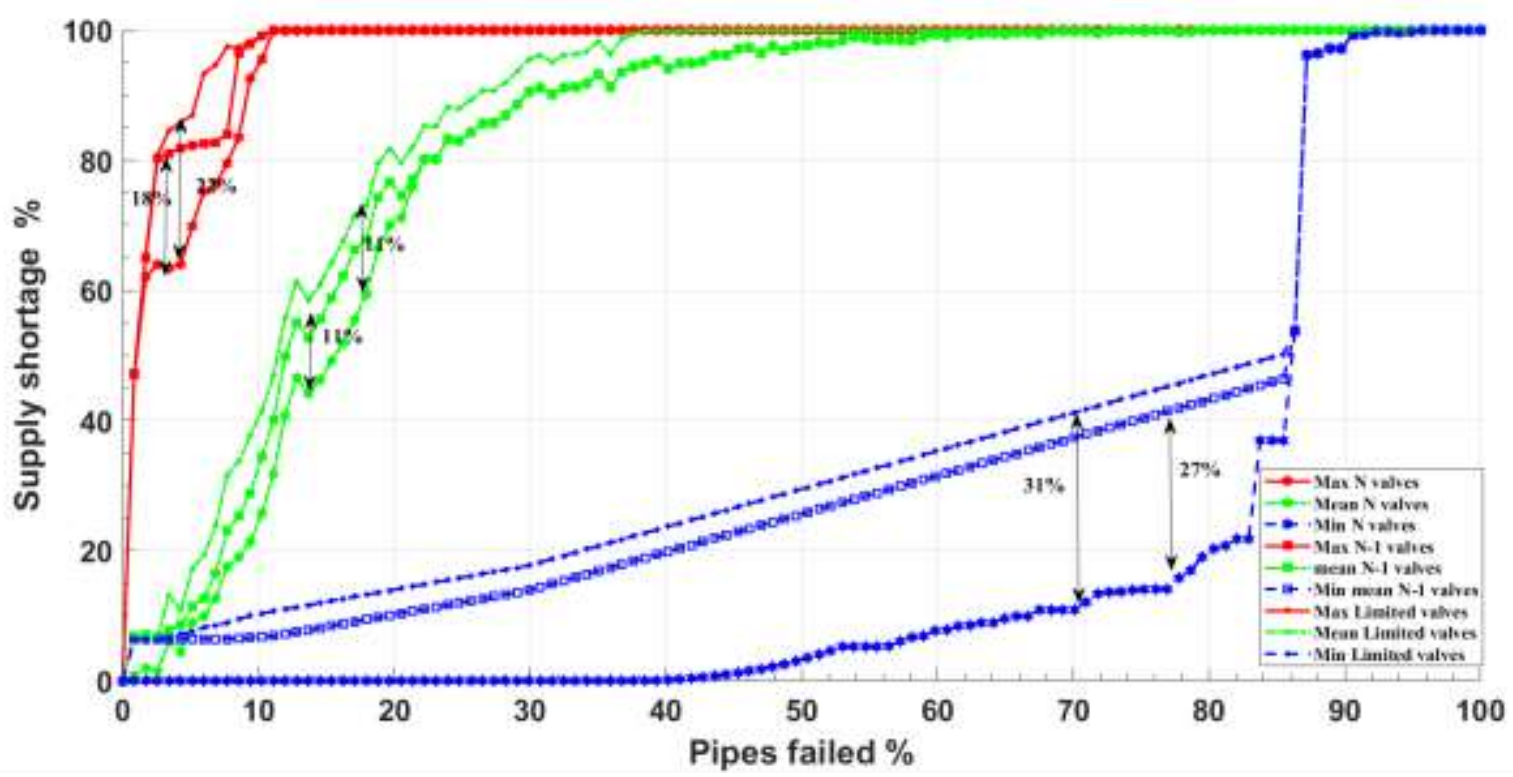

Figure 8 shows the GRA curves of the three different arrangements of isolation valves in

11 Net3. The CRPs were excluded in these analyses. The maximum, mean and minimum resilience of Net3 for $\mathrm{N}$ valves configuration was about $18 \%, 11 \%$, and $27 \%$ higher than the

$13 \mathrm{~N}-1$ valves configuration. The resilience in limited Valves configuration, is about $22 \%, 11 \%$, 14 and $31 \%$ lower than the $\mathrm{N}$ valves in the maximum, mean and minimum, respectively. Thus, 15 by adding approximately 50 valves to the network (converting the limited valves to the $\mathrm{N}-1$ valves configurations) the network resilience increased up to $22 \%$.

17 It should be noted that the critical pipes of Net 3 varied by different valve configurations 
all three configurations. While other critical pipes of the $\mathrm{N}$ valves configurations did not coincide with limited valves and N-1 valves configurations. Thus, the actual location of isolation valves significantly changed the critical pipes of the network (

Figure ).

\section{4-3- Interventions to enhance the resilience}

11 To enhance the resilience of the network addition of isolating valves to the critical segments could be considered. For example, in the limited valves configuration, by adding 4 isolation valves to the critical segments and converting these segments into smaller segments as shown in Figure 12, the resilience increased by $6 \%$.

Figure 13Figure 14 represents the number of isolation valves and pipes in each segment for $\mathrm{N}-1$ and limited valves configurations. In the $\mathrm{N}$ valves configurations, most network pipes have two isolation valves except the branch pipes that have one isolation valve. Table 3 and Table 4 represents the mean and maximum values of network supply shortage for all valve configurations. The most critical segments of $\mathrm{N}-1$ and limited valves configurations are 41 and 13, respectively. Neither of these two segments has the maximum number of pipes and valve, but they have the maximum nodal demand.

\section{5-conclusions} done by closing the adjacent valves. In this study, the effect of valve location on the resilience of WDSs due to pipe failure were analyzed. The resilience of Net3 benchmark systems to three valve configurations ( $\mathrm{N}$ valves, $\mathrm{N}-1$ valves, and limited 
valves) were evaluated. To model the pipe failure mode, it was necessary to find adjacent isolation valves to each pipe in order to isolate a segment including the failed pipe. A method to divide the network to isolated segments based on isolation valves was proposed. The global resilience analysis method was implemented to find out the critical segments. It was shown that the critical segments varied for different valve configurations. The critical pipes can also be changed in different valve configurations. Therefore, the valve configuration can change the global resilience of a water distribution system. It was demonstrated that the resilience can be enhanced by interventions such as adding isolation valves to the critical segments and converting them into smaller portions so that they could be removed from service without affecting much of the system in emergency circumstances.

12 
1. Alvisi, Stefano, Enrico Creaco, and Marco Franchini. 2011. "Segment identification in water distribution systems." Urban Water Journal 8 (4):203-17.

2. Baños, Raúl, Juan Reca, Juan Martínez, Consolación Gil, and Antonio L Márquez. 2011. "Resilience indexes for water distribution network design: a performance analysis under demand uncertainty." Water resources management 25 (10):2351-66.

3. Berardi, Luigi, Rita Ugarelli, Jon Røstum, and Orazio Giustolisi. 2014. "Assessing mechanical vulnerability in water distribution networks under multiple failures." Water Resources Research 50 (3):2586-99.

4. Blokker, Mirjam, Ilse Pieterse-Quirijns, E Postmus, VM Marmelo, and LL Mendes. 2011. "Asset management of valves." Water asset management international 7 (4):12-5.

5. Butler, David, Raziyeh Farmani, Guangtao Fu, Sarah Ward, Kegong Diao, and Maryam Astaraie-Imani. 2014. "A new approach to urban water management: Safe and sure."

6. Butler, David, Sarah Ward, Chris Sweetapple, Maryam Astaraie- Imani, Kegong Diao, Raziyeh Farmani, and Guangtao Fu. 2017. "Reliable, resilient and sustainable water management: the Safe \& SuRe approach." Global Challenges 1 (1):63-77.

7. Creaco, Enrico, Marco Franchini, and Stefano Alvisi. 2010. "Optimal placement of isolation valves in water distribution systems based on valve cost and weighted average demand shortfall." Water resources management 24 (15):4317-38.

8. Dandy, Graeme Clyde, and M Engelhardt. 2001. "Optimal scheduling of water pipe replacement using genetic algorithms." Journal of Water Resources Planning and Management 127 (4):214-23.

9. Diao, Kegong, Chris Sweetapple, Raziyeh Farmani, Guangtao Fu, Sarah Ward, and David Butler. 2016. "Global resilience analysis of water distribution systems." Water research 106:383-93.

10. Francis, Royce, and Behailu Bekera. 2014. "A metric and frameworks for resilience analysis of engineered and infrastructure systems." Reliability Engineering \& System Safety 121:90-103.

11. Fujiwara, Okitsugu, and Jun Li. 1998. "Reliability analysis of water distribution networks in consideration of equity, redistribution, and pressure- dependent demand." Water Resources Research 34 (7):1843-50.

12. Gheisi, Alireza, and Gholamreza Naser. 2014. "Water distribution system reliability under simultaneous multicomponent failure scenario." Journal-American Water Works Association 106 (7):E319-E27.

13. Giustolisi, Orazio. 2018. "Development of a modularity index for reliability assessment of isolation valve systems." EPiC Series in Engineering 3:800-9.

14. Giustolisi, Orazio, Luigi Berardi, and D Laucelli. 2014. "Optimal water distribution network design accounting for valve shutdowns." Journal of Water Resources Planning and Management 140 (3):277-87. 
15. Giustolisi, Orazio, Zoran Kapelan, and Dragan Savic. 2008. "Algorithm for automatic detection of topological changes in water distribution networks." Journal of Hydraulic Engineering 134 (4):435-46.

16. Giustolisi, Orazio, and Dragan Savic. 2010. "Identification of segments and optimal isolation valve system design in water distribution networks." Urban Water Journal 7 (1):1-15.

17. Hashimoto, Tsuyoshi, Jery R Stedinger, and Daniel P Loucks. 1982. "Reliability, resiliency, and vulnerability criteria for water resource system performance evaluation." Water Resources Research 18 (1):14-20.

18. Hokstad, Per, Ingrid B Utne, and Jørn Vatn. 2012. Risk and interdependencies in critical infrastructures: Springer. " Reliability Engineering \& System Safety, 120, pp.27-38.

19. Johansson, Jonas, Henrik Hassel, and Enrico Zio. 2013. "Reliability and vulnerability analyses of critical infrastructures: comparing two approaches in the context of power systems." Reliability Engineering \& System Safety 120:27-38.

20. Johansson, Jonas. 2007. "Risk and vulnerability analysis of large-Scale technical infrastructures." PhD Report, Lund University.

21. Jose, Nekha, and KS Sumam. 2016. "Optimal water distribution network design accounting for valve closure." Procedia Technology 24:332-8.

22. Jun, Hwandon. 2005. "Strategic valve locations in a water distribution system." Virginia Tech.

23. Jun, Hwandon, and GV Loganathan. 2007. "Valve-controlled segments in water distribution systems." Journal of Water Resources Planning and Management 133 (2):145-55.

24. Kao, Jehng- Jung, and Pei- Hao Li. 2007. "A segment- based optimization model for water pipeline replacement." Journal-American Water Works Association 99 (7):8395.

25. Klise, Katherine A, Regan Murray, and Terra Haxton. 2018. "An Overview of the Water Network Tool for Resilience (WNTR)." In.: Sandia National Lab.(SNL-NM), Albuquerque, NM (United States).

26. Lakes, Great, and Upper Mississippi River Board. 1992. Recommended Standards for Water Works: The Board.

27. Liu, Haixing, Tom Walski, Guangtao Fu, and Chi Zhang. 2017. "Failure impact analysis of isolation valves in a water distribution network." Journal of Water Resources Planning and Management 143 (7):04017019.

28. Mays, Larry W. 2000. Water distribution systems handbook: McGraw-Hill.

29. Meng, Fanlin, Chris Sweetapple, and Guangtao Fu. 2018. Placement of Isolation Valves for Resilience Management of Water Distribution Systems. Paper presented at the WDSA/CCWI Joint Conference Proceedings. 
30. Monsef, H, M Naghashzadegan, R Farmani, and A Jamali. 2019. "Deficiency of reliability indicators in water distribution networks." Journal of Water Resources Planning and Management 145 (6):04019022.

31. Mugume, Seith N, Diego E Gomez, Guangtao Fu, Raziyeh Farmani, and David Butler. 2015. "A global analysis approach for investigating structural resilience in urban drainage systems." Water research 81:15-26.

32. Paez, D, Y Fillion, and M Hulley. 2018. Battle of post-disaster response and restauration (BP-DRR): Problem description and rules. Paper presented at the 1st International Water Distribution System Analysis/Computing and Control in the Water Industry Joint Conference, Kingston, ON, Canada, 23-25 July 2018.

33. Pathirana, Assela. 2010. "EPANET2 desktop application for pressure driven demand modeling." In Water Distribution Systems Analysis 2010, 65-74.

34. Pecci, Filippo, Edo Abraham, and Ivan Stoianov. 2017. "Penalty and relaxation methods for the optimal placement and operation of control valves in water supply networks." Computational Optimization and Applications 67 (1):201-23.

35. Rosenthal, Loet, George Mesman, and Martin De Koning. 2002. Key criteria for valve operation and maintenance: AWWA Research Foundation.

36. Rossman, Lewis A. 2000. "EPANET 2: users manual."

37. Sweetapple, Chris, K Diao, R Farmani, G Fu, and D Butler. 2018. A tool for global resilience analysis of water distribution systems. Paper presented at the WDSA/CCWI Joint Conference 2018.

38. Tabesh, M, J Soltani, R Farmani, and D Savic. 2009. "Assessing pipe failure rate and mechanical reliability of water distribution networks using data-driven modeling." Journal of Hydroinformatics 11 (1):1-17.

39. Todini, Ezio. 2000. "Looped water distribution networks design using a resilience index based heuristic approach." Urban water 2 (2):115-22.

40. Wagner, Janet M, Uri Shamir, and David H Marks. 1988. "Water distribution reliability: simulation methods." Journal of Water Resources Planning and Management 114 (3):276-94.

41. Walski, Thomas M. 1987. "Discussion of "Quantitative Approaches to Reliability Assessment in Pipe Networks" by IC Goulter and AV Coals (May, 1986, Vol. 112, No. 3)." Journal of Transportation Engineering 113 (5):585-7.

42. Walski, Thomas M. 1993. "Water distribution valve topology for reliability analysis." Reliability Engineering \& System Safety 42 (1):21-7.

43. Walski, Thomas M. 2002. Issues in providing reliability in water distribution systems. Paper presented at the ASCE EWRI Conference, Roanoke, VA.

44. Walski, Thomas M, Justin Sterling Weiler, and Teresa Culver. 2008. Using criticality analysis to identify impact of valve location. Paper presented at the Water Distribution Systems Analysis Symposium 2006.

45. Ysusi, Mark A. 1999. "Water distribution system design." Mays, LW Hydraulic Design Handbook. McGraw Hill, New York, NY. 
Table 1. Properties of Net3 for different valve configuration

\begin{tabular}{ccccccccc}
\hline Configuration & Junctions & Pipes & Reservoirs & Tanks & Pumps & Isolation valves & Segments & Demand \\
\hline Without valves & 91 & 115 & 2 & 3 & 2 & 0 & 0 & 717.3 \\
With $N$ valves & 510 & 327 & 2 & 3 & 2 & 228 & 114 & 717.3 \\
With $N-1$ valves & 302 & 222 & 2 & 3 & 2 & 105 & 80 & 717.3 \\
With Limited valves & 195 & 167 & 2 & 3 & 2 & 52 & 30 & 717.3 \\
\hline 2 & & & & & & & &
\end{tabular}

3

4

5

6

7

8

9

10

11

12

13

14

15

16

17

18

19

20

21 
Table 2. Critical pipes for different valve configurations

\begin{tabular}{ccccccccccc}
\hline Model & \multicolumn{10}{c}{ Critical pipes ID } \\
\hline $\boldsymbol{N}$ valves & 233 & 193 & 247 & 201 & 129 & 330 & 333 & 113 & 125 & 217 \\
$N-1$ valves & 233 & 231 & 323 & 329 & 125 & 122 & 123 & 129 & 315 & 193 \\
limited valves & 233 & 231 & 323 & 317 & 239 & 122 & 123 & 129 & 125 & 329 \\
\hline
\end{tabular}

2

3

4

5

6

7

8

9

10

11

12

13

14

15

16

17

18

19

20

21

22 
Table 3. Average supply shortage for all valve configurations

\begin{tabular}{cccc}
\hline Valve configuration & $\begin{array}{c}\text { Average No. of valves } \\
\text { for segment isolation }\end{array}$ & $\begin{array}{c}\text { Average No. of pipe in } \\
\text { segments }\end{array}$ & $\begin{array}{c}\text { Average supply } \\
\text { shortage when one } \\
\text { pipe failed (\%) }\end{array}$ \\
\hline $\boldsymbol{N}$ valves & 1.92 & 1 & 8.24 \\
$\boldsymbol{N}-1$ valves & 2.58 & 2.65 & 9.44 \\
Limited valves & 3.1 & 5 & 11.9 \\
\hline
\end{tabular}


Table 4. Maximum number of valves in each segment for different valve configurations

\begin{tabular}{ccc}
\hline & $\begin{array}{c}\text { maximum No. of valves for } \\
\text { isolation each segment }\end{array}$ & $\begin{array}{c}\text { maximum No. of pipe in } \\
\text { segments }\end{array}$ \\
\hline $\boldsymbol{N}$ valves & 2 & 1 \\
$N$-1 valves & 5 & 6 \\
Limited valves & 6 & 11 \\
\hline
\end{tabular}

1

2

3

4 


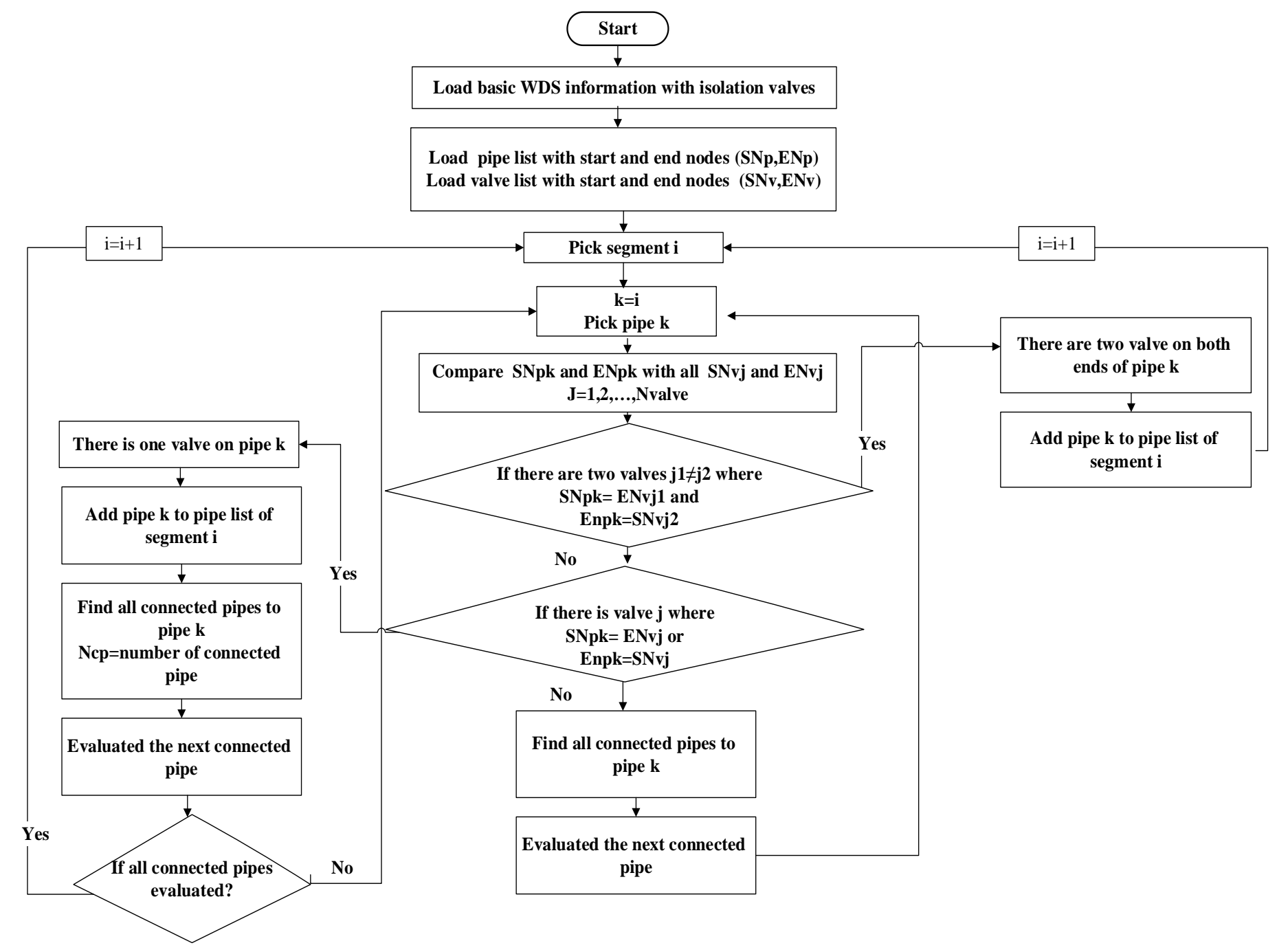

1

2 Figure 1. A flowchart to find the adjacent isolation valves of each pipe in a WDS

3

4

5

6 


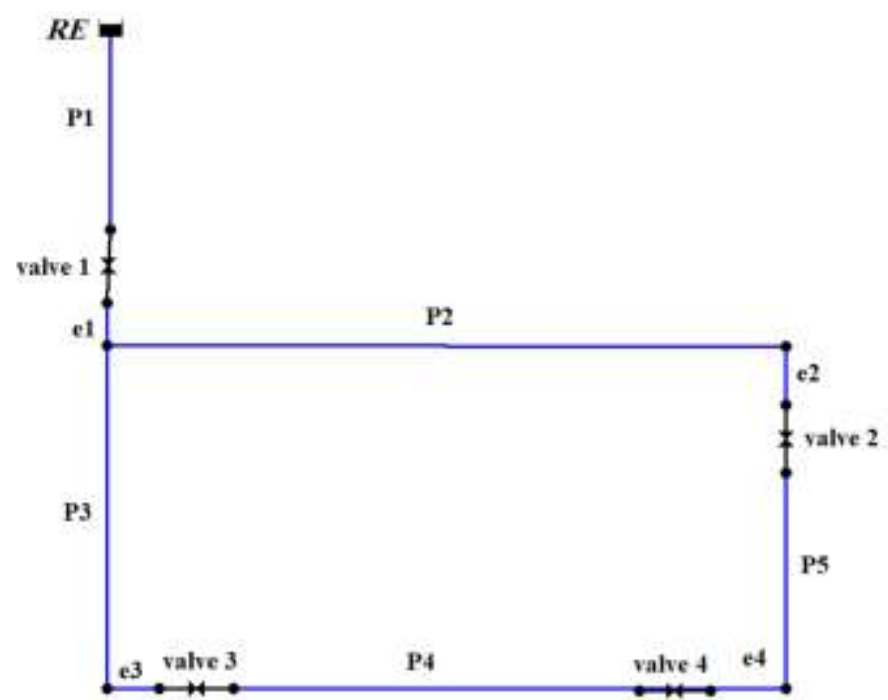

Figure 2. An example of WDS 


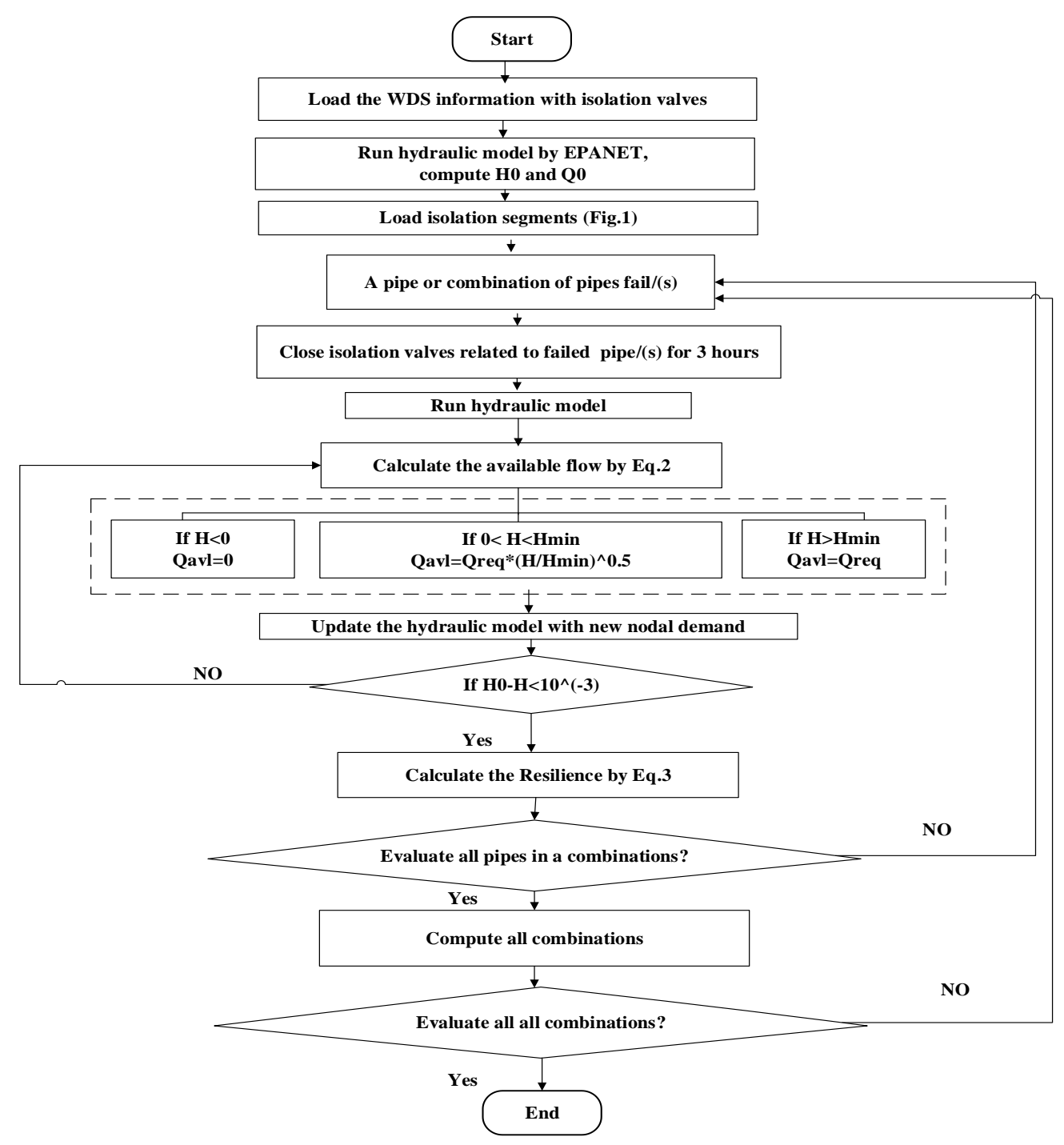

1 Figure 3. The flowchart for resilience analysis of pipe failure in WDS by isolation valves 


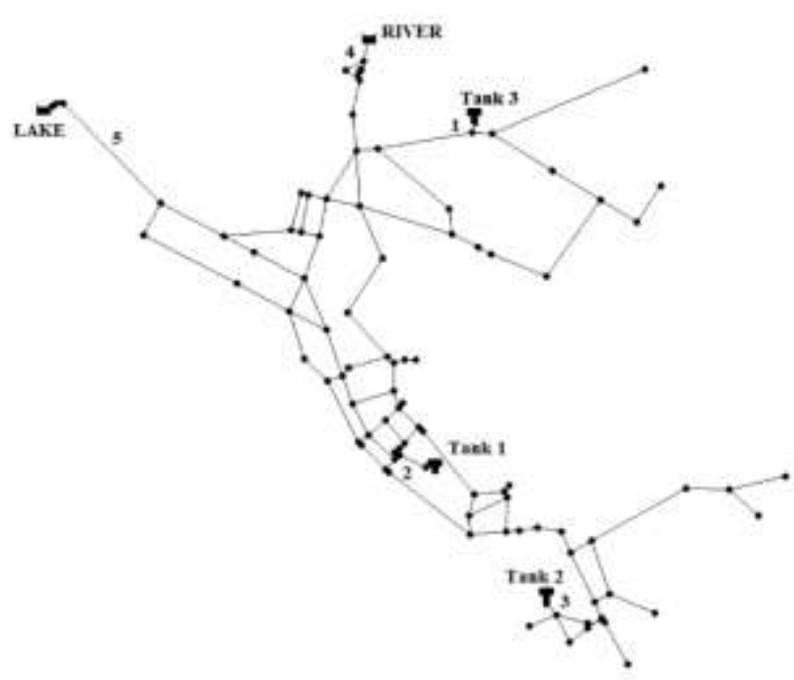

(a)

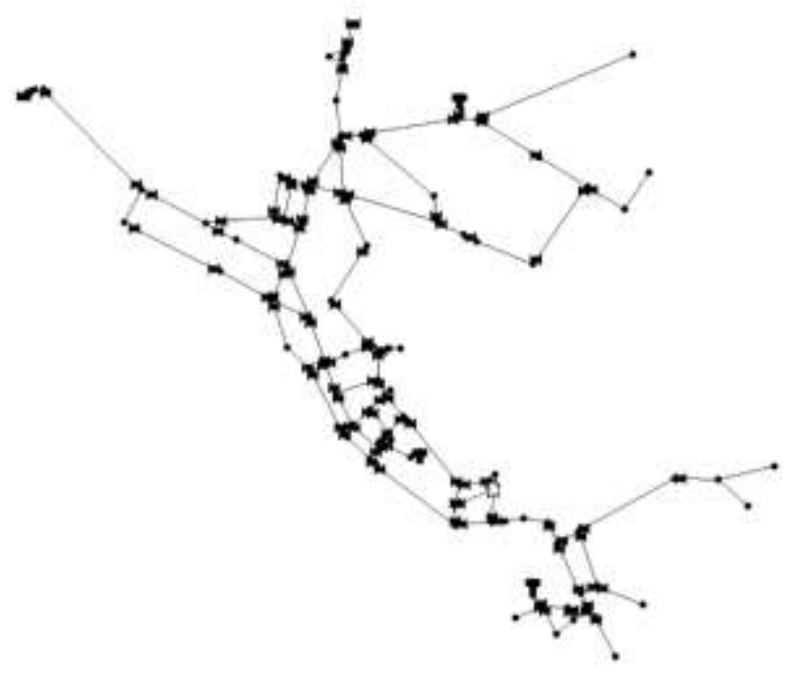

(c)

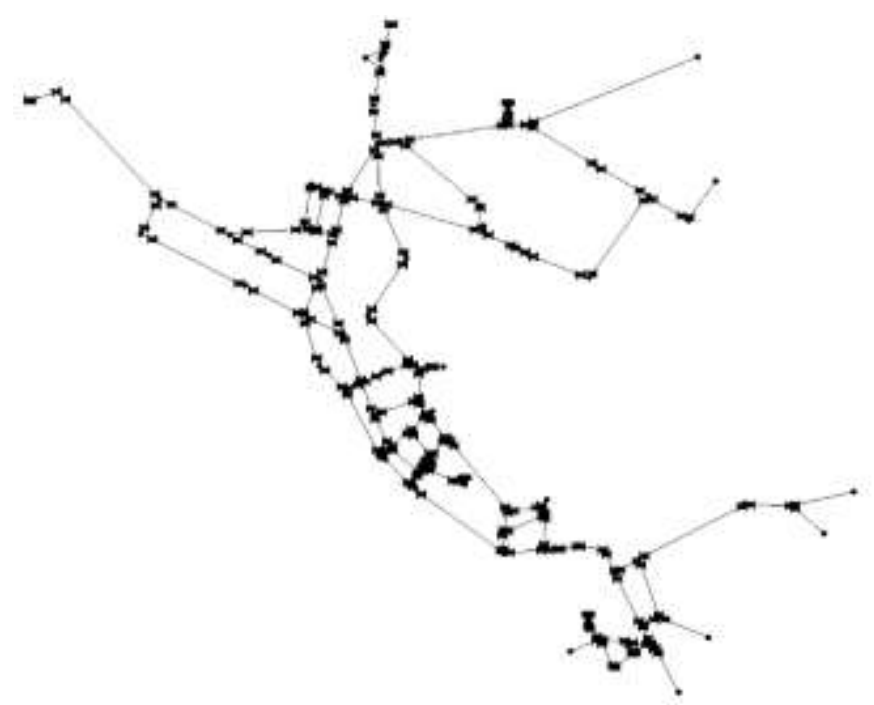

(b)

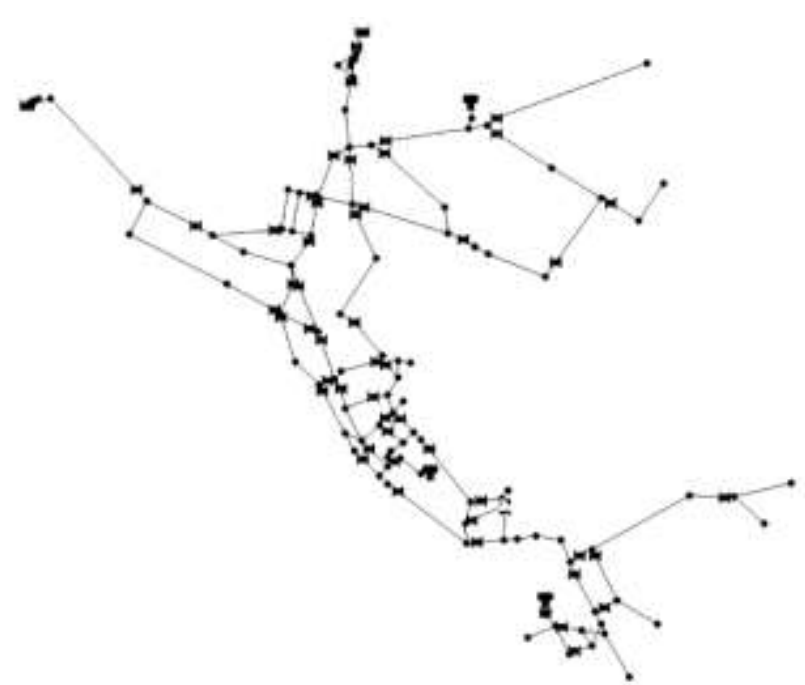

(d)

Figure 4. a) Net3 without valve b) N valves c) N-1 valves and d) Limited valves configurations 


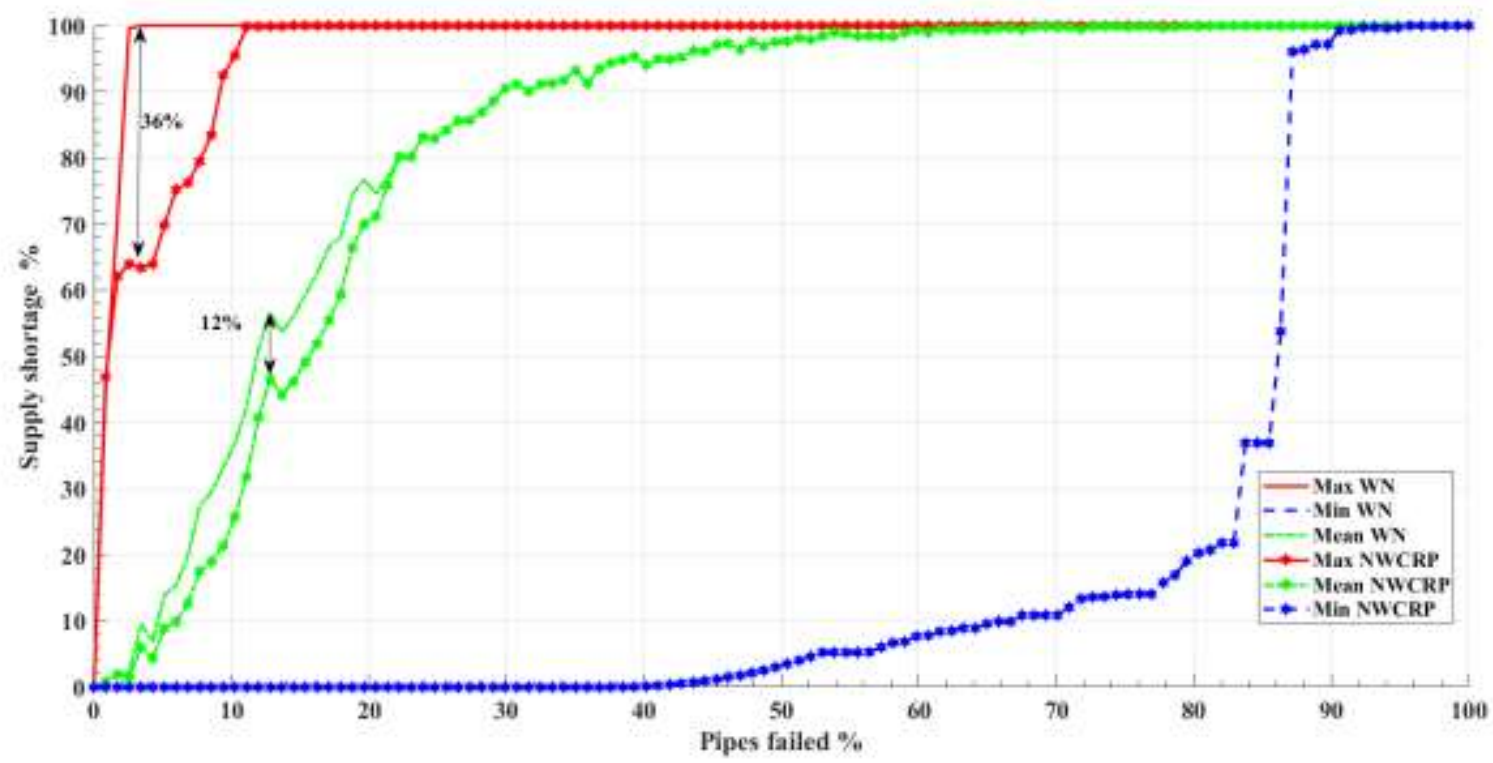

Figure 5. Supply shortage for the whole network(WN) and the network without CRP 3 $(\mathrm{NWCRP}))$ 


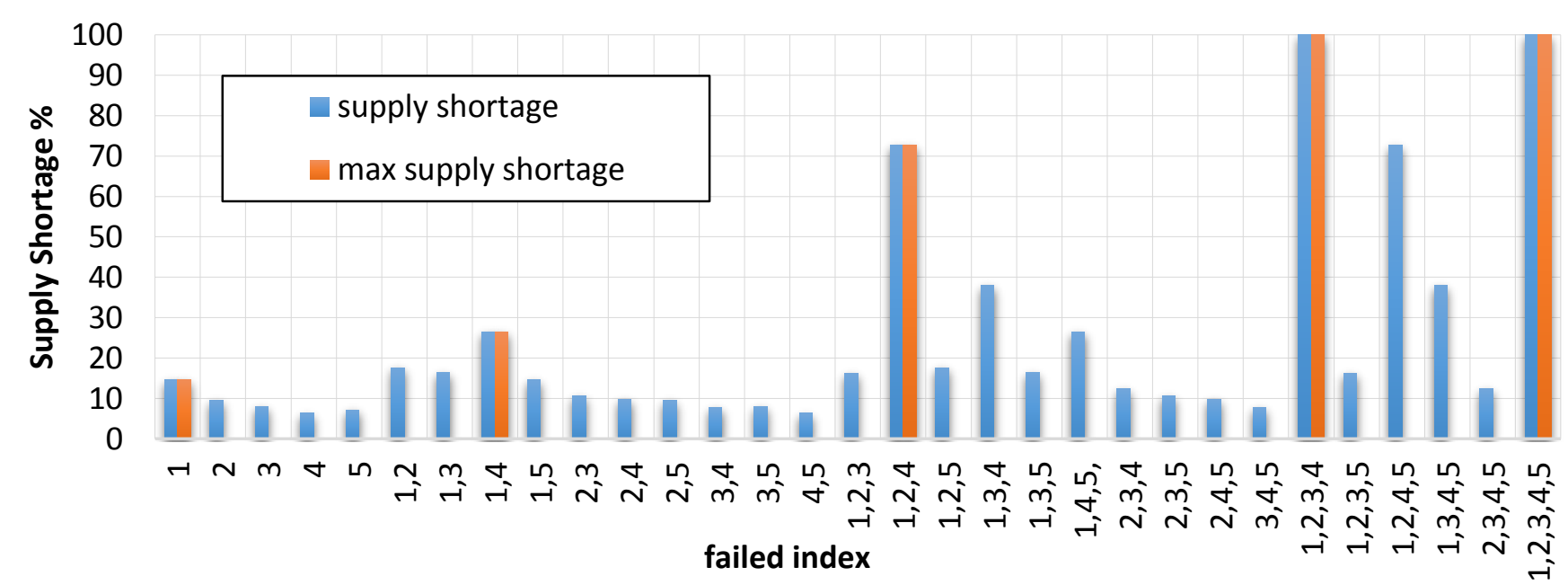

Figure 6. Supply Shortage for all combination of CRP failure

4 


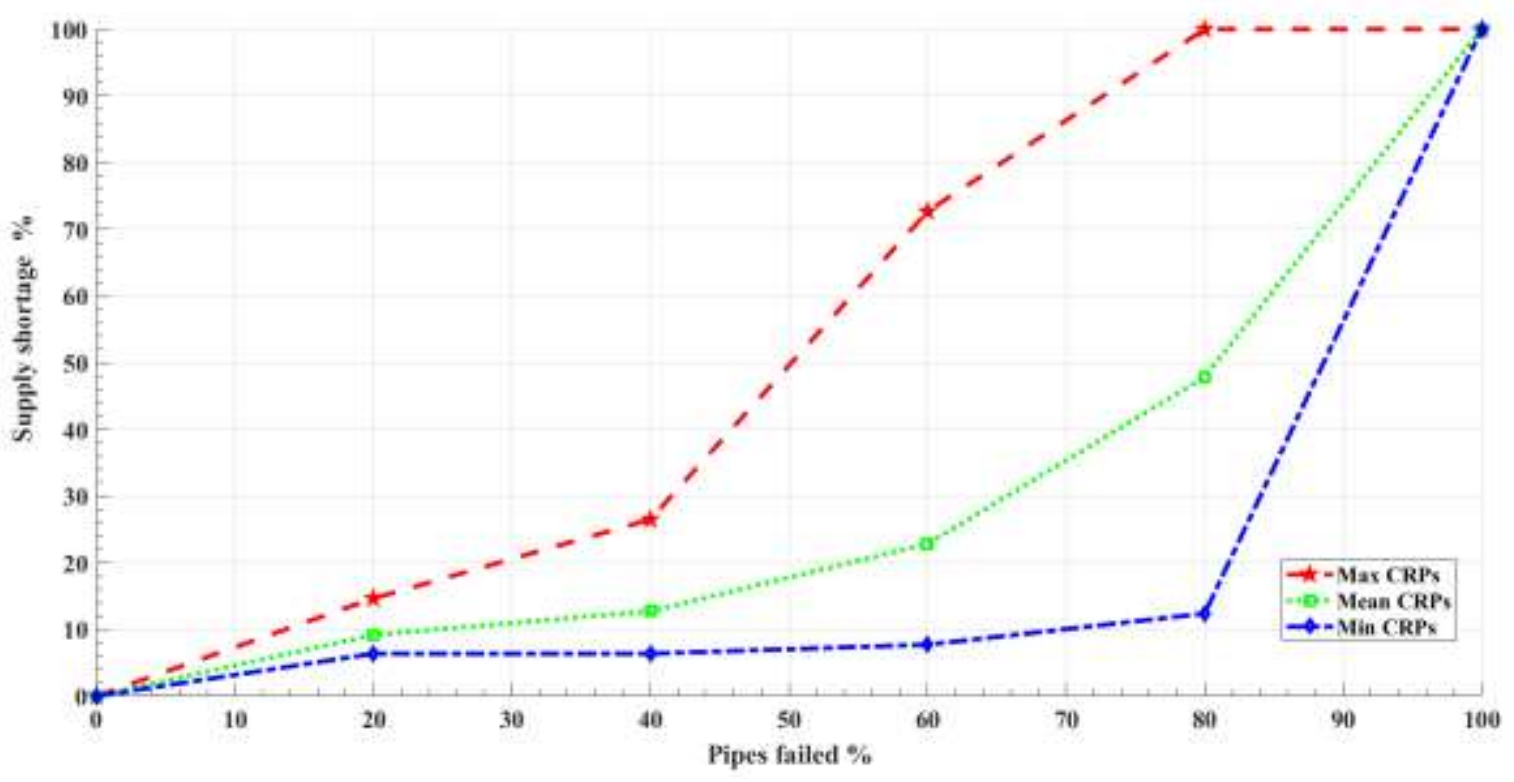

Figure 7. Supply shortage for CRP failures

3

4

5

6

7

8

9

10

11

12

13 


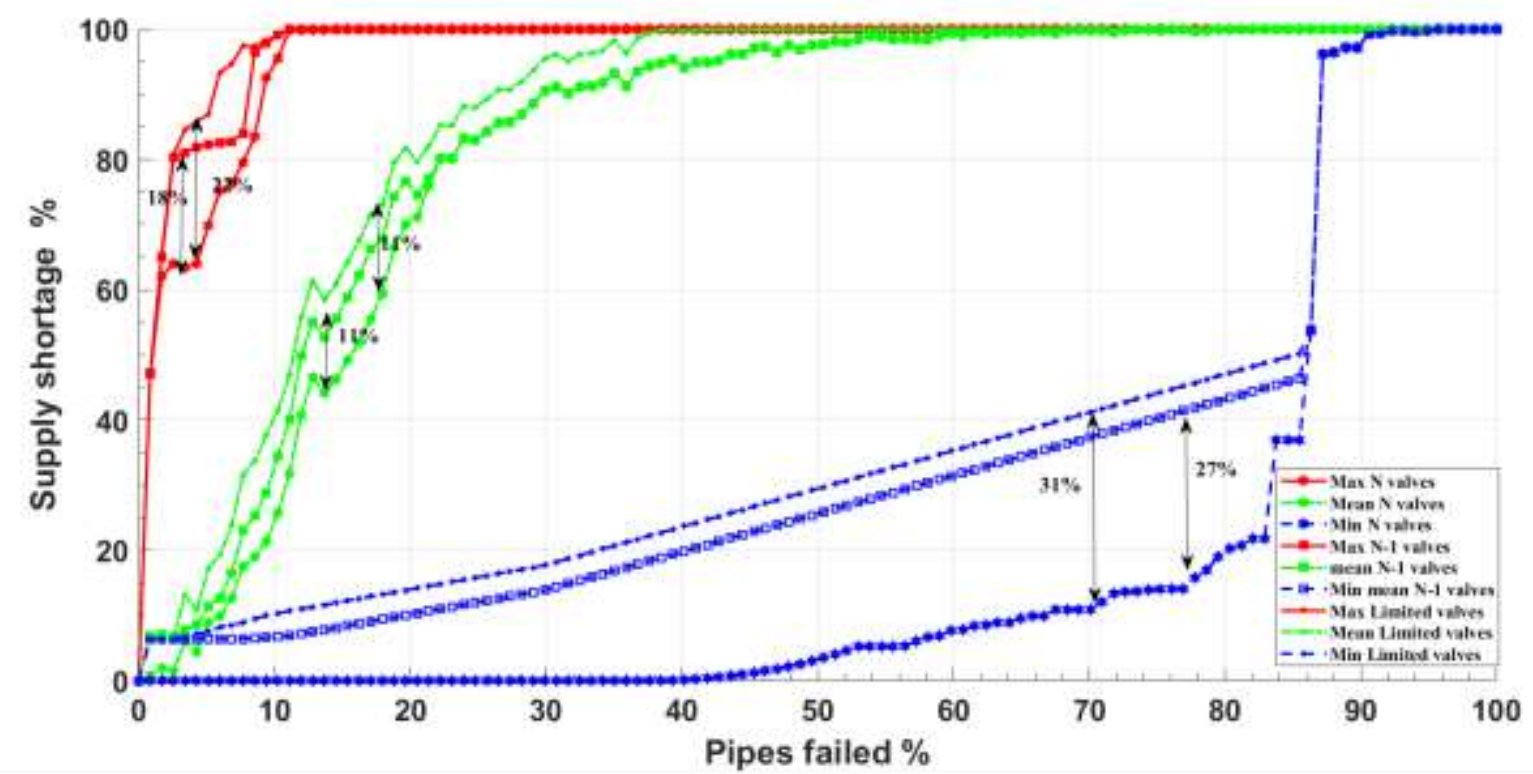

3

Figure 8. GRA curves for three valve configurations

5

6

7

8

9

10

11 


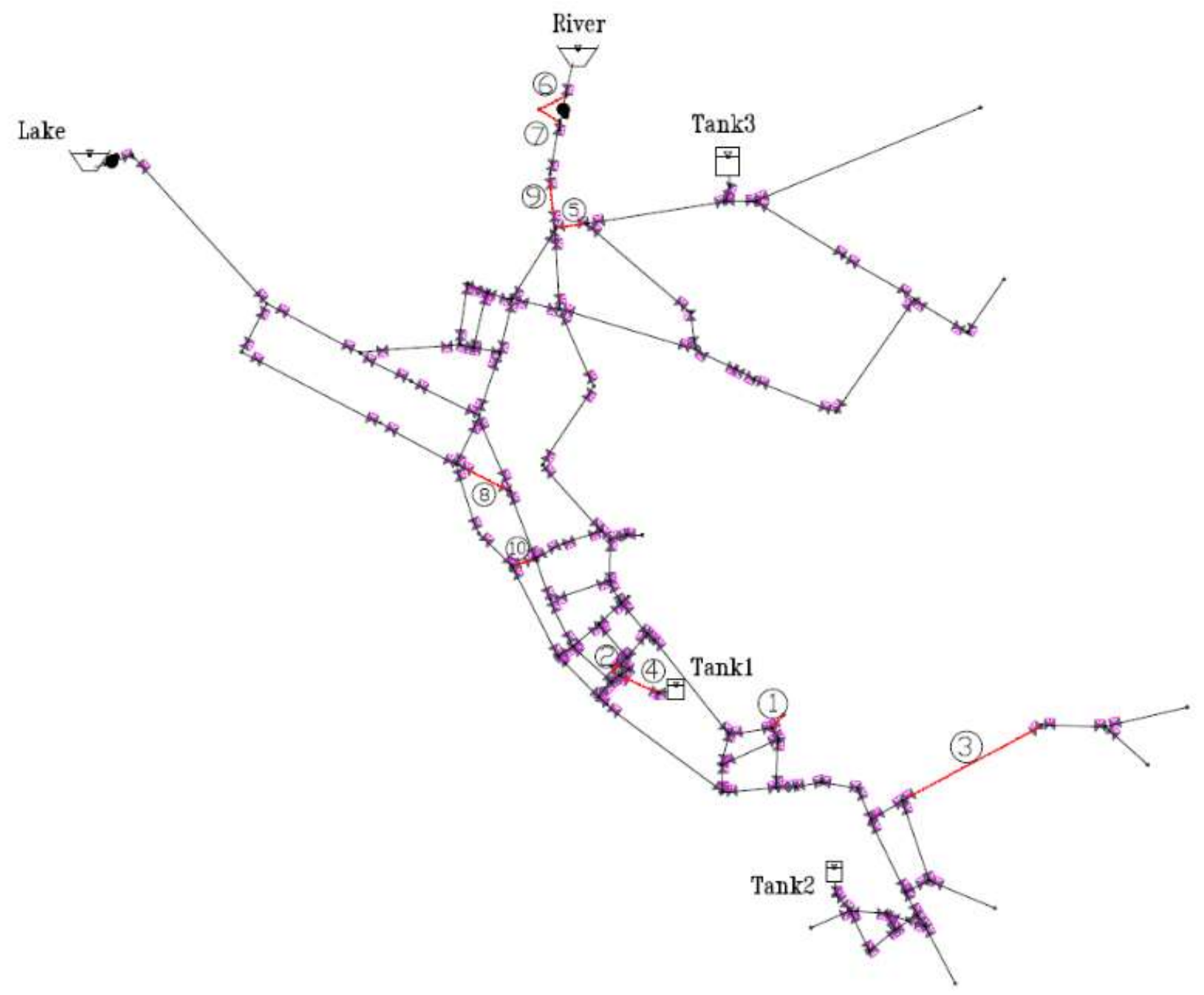

4

5

Figure 9. Critical pipes in N-valves configurations 


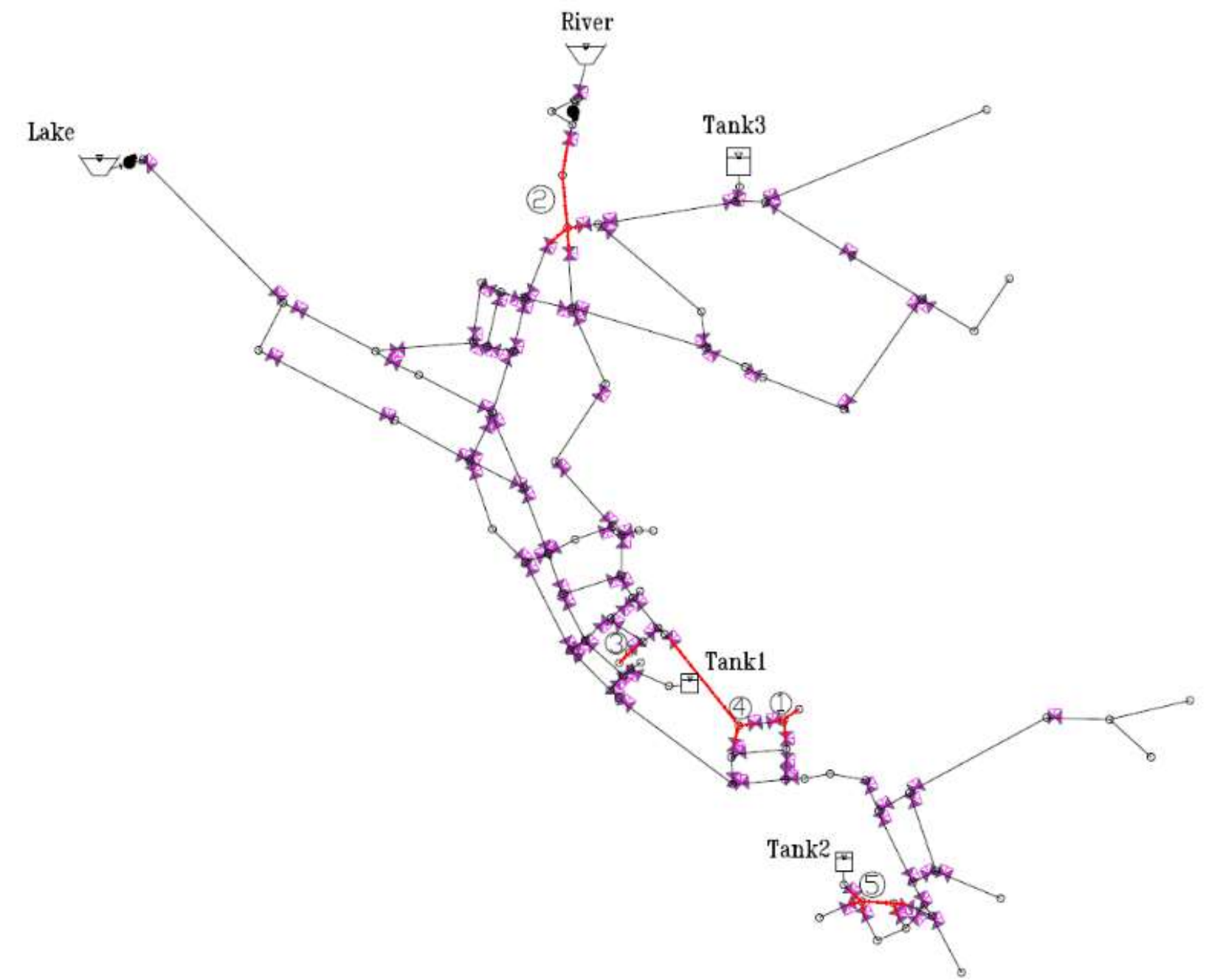




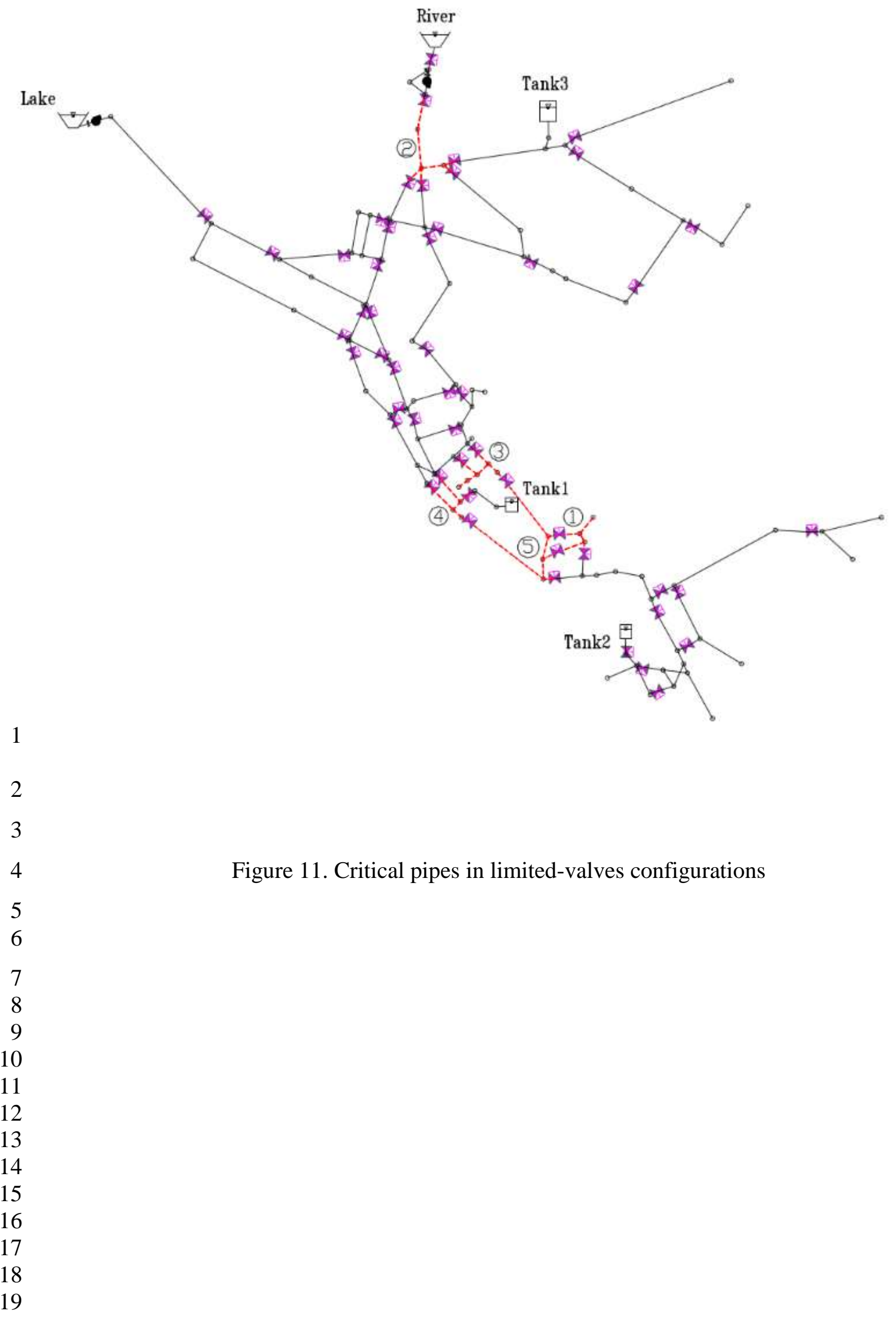




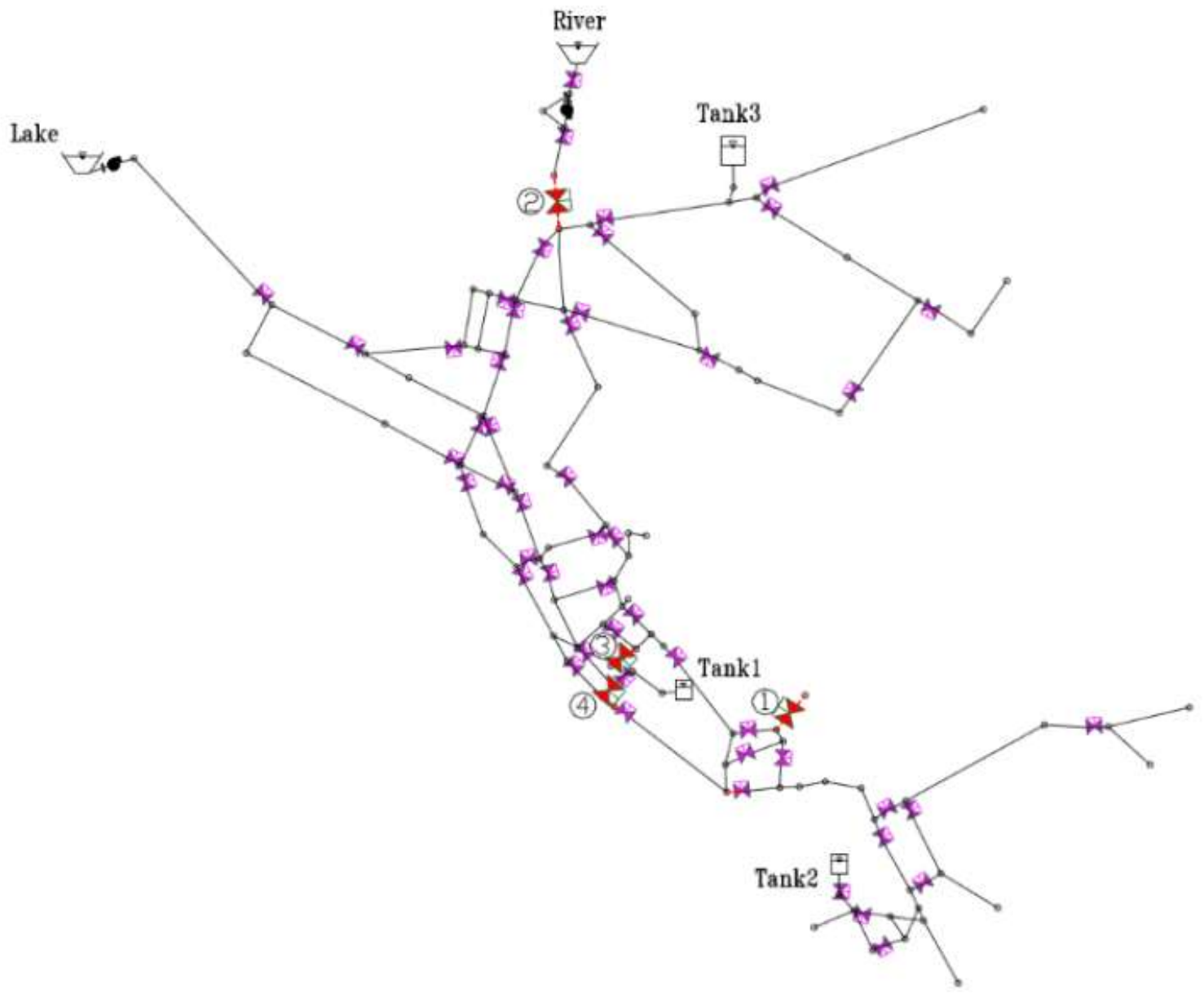

2

3

4

Figure 12. Adding 4 isolation valve to the critical segments in limited valves configurations 5 


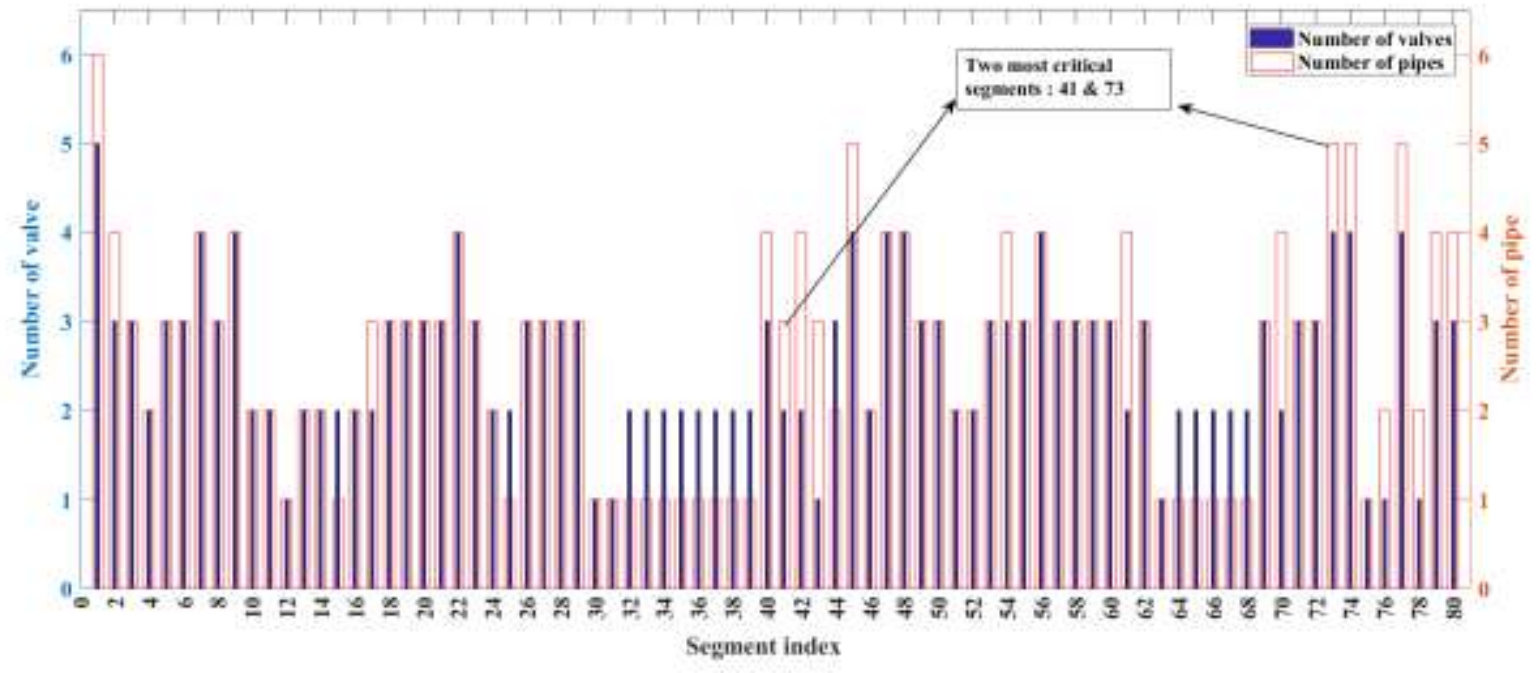

Figure 13. Number of valves and pipes in segment for $\mathrm{N}-1$ valves configurations 


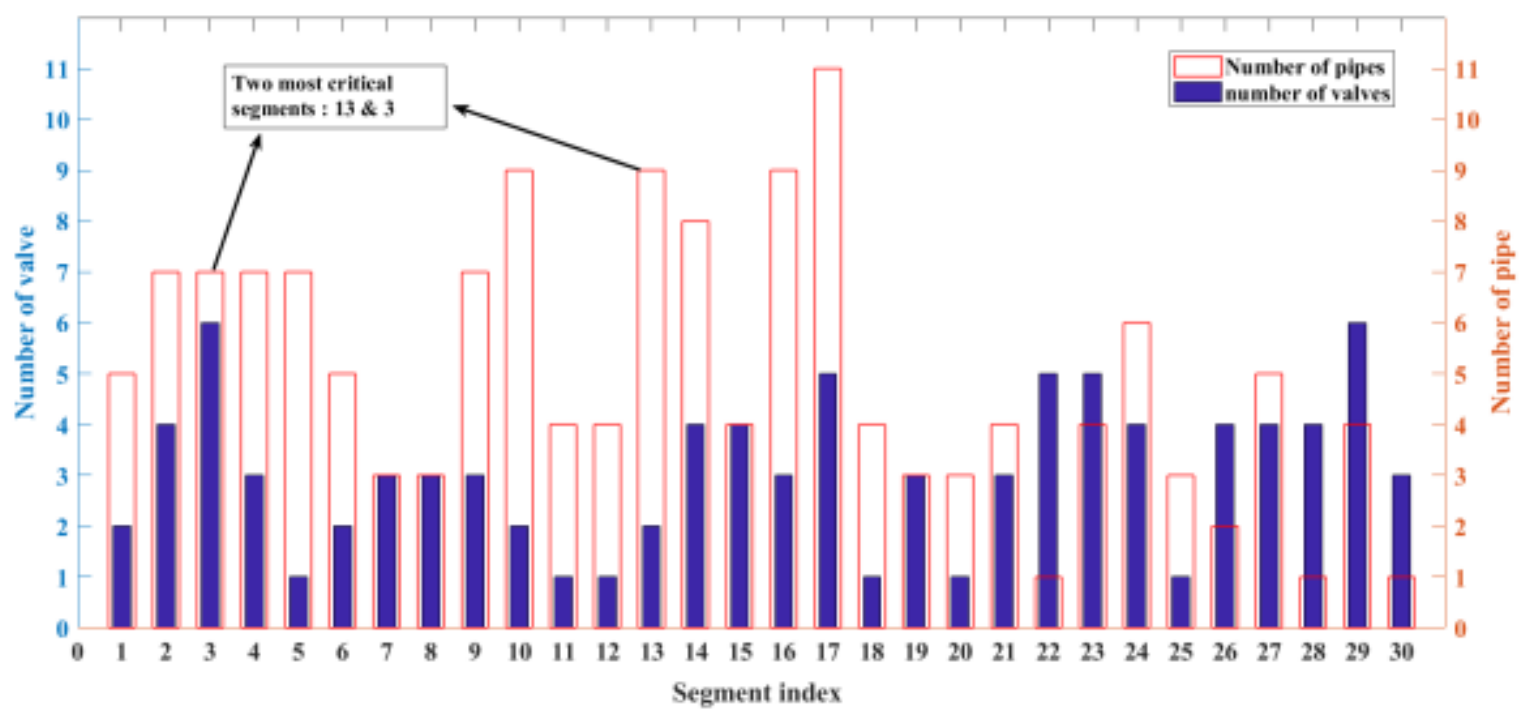

3

Figure 14. Number of valves and pipes in segment for limited valves configurations

5

6

7 